\title{
Hydrogen infrastructure development in The Netherlands
}

\author{
Ruben Smit, Marcel Weeda*, Arend de Groot \\ Energy Research Centre of The Netherlands (ECN), P.O. Box 1, 1755 ZG Petten, The Netherlands
}

Available online 30 November 2006

\begin{abstract}
Increasingly people think of how a hydrogen energy supply system would look like, and how to build and end up at such a system. This paper presents the work on modelling and simulation of current ideas among Dutch hydrogen stakeholders for a transition towards the widespread use of a hydrogen energy. Based mainly on economic considerations, the ideas about a transition seem viable. It appears that following the introduction of hydrogen in niche applications, the use of locally produced hydrogen from natural gas in stationary and mobile applications can yield an economic advantage when compared to the conventional system, and can thus generate a demand for hydrogen. The demand for hydrogen can develop to such an extent that the construction of a large-scale hydrogen pipeline infrastructure for the transport and distribution of hydrogen produced in large-scale production facilities becomes economically viable. In 2050, the economic viability of a large-scale hydrogen pipeline infrastructure spreads over 20-25 of the 40 regions in which The Netherlands is divided for modelling purposes. Investments in hydrogen pipelines for a fully developed hydrogen infrastructure are estimated to be in the range of 12,000-20,000 million euros.
\end{abstract}

(C) 2006 International Association for Hydrogen Energy. Published by Elsevier Ltd. All rights reserved.

Keywords: Hydrogen; Hydrogen infrastructure; Hydrogen pipelines; Cost of hydrogen; Hydrogen demand; Fuel cell vehicles; Micro-combined heat and power; $\mu \mathrm{CHP}$

\section{Introduction}

Hydrogen is seen as a promising energy carrier for our future energy system. Besides activities in technology development, increasingly people start to think of how such an energy system would look like, and how to start building and to end up at such a system. Within The Netherlands, Dutch hydrogen stakeholders ${ }^{1}$ thus far have developed the following picture within the framework of the European HyWays project [1]:

- The application of hydrogen will start with niche applications distributed around the country. This includes, for example, city buses in areas facing air quality problems, and the use of hydrogen forklifts in warehouses and centre for distribution of goods.

\footnotetext{
* Corresponding author. Tel.: +31 224564495; fax: +31 224568504 .

E-mail address: weeda@ecn.nl (M. Weeda).

${ }^{1}$ Stakeholders range from universities and research institutes to local and national authorities, and from small companies in the area of smallscale reformers (HyGear) and fuel cells (Nedstack) to large gas and energy companies like Air Products, Shell and Gasunie.
}

- In the future, the main application of hydrogen is in the transportation sector, and in the residential and commercial sector (combined heat and power (CHP)).

- Due to the lack of an infrastructure ${ }^{2}$ for transport and distribution of hydrogen on the one hand, and the presence of a well-developed natural gas pipeline infrastructure on the other hand, initially hydrogen will be produced on-site through steam reforming of natural gas.

- After the initial stage, the local hydrogen communities and refuelling stations will be connected to a larger hydrogen transport and distribution pipeline infrastructure, and local production will be supplemented and finally replaced by large-scale production facilities which offer the possibility for applying carbon capture and storage.

- Hydrogen from renewable sources (offshore wind and biomass) will only start to play a role when a significant part of the large-scale pipeline infrastructure is in place and the cost of hydrogen are comparable with hydrogen from natural gas and coal.

\footnotetext{
${ }^{2}$ Throughout this paper "hydrogen infrastructure" means a pipeline infrastructure for transport and distribution of hydrogen.
} 
- Based on the existence of large-scale hydrogen production facilities and an industrial pipeline infrastructure for transport of hydrogen, already today, the Rotterdam area is considered to be the starting point for the development of a large-scale hydrogen pipeline infrastructure.

By mixing these ingredients, a transition scenario starts to arise. But it is still a qualitative story. There is a need to quantify the story to get a feeling of its viability. In practice there will be many aspects and events influencing the transition. For instance, public acceptance and spatial planning are issues that may affect the course and speed of a transition considerably. However, these issues are difficult to quantify. Therefore, as a start, the work presented in this paper is largely based on costs and economic considerations.

\section{Objectives}

The main objective of the work presented in this paper is to quantify the Dutch hydrogen transition ideas to test the viability of the ideas, and to get some feeling for the answers to important questions like:

- Can a demand for hydrogen develop in The Netherlands if the hydrogen is produced with on-site steam methane reforming, and how fast may the demand for hydrogen develop?

- When and where could a hydrogen pipeline infrastructure evolve in The Netherlands, and what would be the cost?

\section{Methods and assumptions}

A model is developed in Excel, which, in basically three steps, determines whether and when a hydrogen infrastructure could develop in The Netherlands. The steps are indicated in Fig. 1. In the model, The Netherlands is divided into 40 regions. The regions correspond to the regional division used by the Dutch statistics agency to collect all kinds of statistical data. A number of these data, like type and number of houses, number of houses built annually, number of cars and annual car sales, are used to determine the potential number of future hydrogen consumers.
Two types of hydrogen applications are considered in the present study, viz. CHP production for households using a PEMFC-based micro-CHP system ( $\mu \mathrm{CHP}$ system), and transportation using a vehicle with a PEMFC-based drive train (FC-car). A natural gas fuelled condensing boiler together with electricity from the Dutch public grid is used as the reference system for the supply of heat and power in a household. In the case of transportation a gasoline fuelled car with internal combustion engine is used as the reference system.

Based on a comparison between the cost for the energy services supplied by the hydrogen system and the reference system, and an analysis of the potential number of hydrogen consumers, the model first calculates the development in the demand of hydrogen in each of the 40 regions in The Netherlands for the years 2010-2050. In the second step, the model calculates what the cost of a hydrogen infrastructure would be if the hydrogen would be supplied by such an infrastructure right from the start is calculated, instead of first being supplied by on-site facilities. This is referred to as the "theoretical builtup of the hydrogen infrastructure". Finally, in the third step the contribution of the "theoretical hydrogen infrastructure" to the cost of hydrogen is compared with the difference in cost of hydrogen from on-site and large-scale facilities, to evaluate for each region when it could become economically feasible to actually construct a hydrogen infrastructure.

The main input parameters for the three steps are listed in Tables 1-4 and are called the "base case" scenario. The energy services cost are assumed to change from year to year mainly due to changes in the price of the energy carriers and in the fuel cell system cost. The European Energy and Transport-Trends to 2030 [2] is used as a reference for the development of prices of energy carriers. The fuel cell system cost constitutes an important input parameter in the model. The cost is assumed to decrease as a function of time according to the following equations:

$$
\begin{aligned}
& C(t)_{\mathrm{FC}}=C_{\mathrm{FC}, 2002}\left(\frac{C_{\mathrm{FC}, 2010}}{C_{\mathrm{FC}, 2002}}\right)^{(t-2002) /(2010-2002)}, \\
& C(t)_{\mathrm{FC}}=C_{\mathrm{FC}, 2010}\left(\frac{C_{\mathrm{FC}, 2050}}{C_{\mathrm{FC}, 2010}}\right)^{(t-2010) /(2050-2010)},
\end{aligned}
$$

where $C(t)_{\mathrm{FC}}$ is the fuel cell system cost in a certain year and $t$ is the year for which the fuel cell system cost is calculated. The cost curve is split into two parts. The first part runs from the year 2002 till 2010 and the second part runs from the year 2010-2050. The splitting is based on the assumption that in an introduction phase the fuel cell system cost will go down relatively fast, while in a later stage, when the technology reaches a higher level of maturity, it becomes increasingly difficult to further reduce the cost. The fuel cell costs used in the years 2002, 2010 and 2050 to construct the cost curves are given in Tables 1 and 2. The fuel cell system cost for a $\mu \mathrm{CHP}$ system is assumed higher than for a FC-car because of the smaller unit size and higher quality requirements resulting from a larger number of running hours for stationary systems. The difference in cost by a factor of two, however, is chosen more or less arbitrarily.

Fig. 1. Schematic overview of the model. 
Table 1

Main input data for calculation of hydrogen demand from $\mu \mathrm{CHP}$ systems

Fuel cell system cost

Application potential

Average annual energy demand in a

household

Control strategy $\mu \mathrm{CHP}$ system

Cost of natural gas (2004)

Cost increase natural gas

Cost of electricity (2004)

Cost increase electricity

Cost hydrogen distribution pipelines

houses

Power output

$\mu \mathrm{CHP}$ fuel cell efficiency

Payback time $\mu \mathrm{CHP}$ system
$5000 € / \mathrm{kW}$ in $2002,500 € / \mathrm{kW}$ in 2010 and $100 € / \mathrm{kW}$ in 2050 for stationary fuel cells.

$1.05 \% / y e a r$ newly built houses, $1.50 \% /$ year renovated houses

Natural gas for space heating: linear relation from $1000 \mathrm{~N} \mathrm{~m}^{3} /$ year in 2002 to $657 \mathrm{~N} \mathrm{~m}^{3} /$ year in 2050. Electricity: linear relation from $3056 \mathrm{~kW}$ h/year in 2002 to $6017 \mathrm{~kW} \mathrm{~h} /$ year in 2050. Natural gas for warm water: constant at $310 \mathrm{~N} \mathrm{~m}^{3} /$ year [2]

Heat-demand following strategy. Feed in tariff for electricity equals the commodity cost of electricity for residential consumers: $0.055 € / \mathrm{kW} \mathrm{h}$

$0.059 € / \mathrm{kW} \mathrm{h}\left(0.517 €_{/} / \mathrm{N} \mathrm{m}^{3}\right)$

$1.5 \%$ per year

$0.196 € / \mathrm{kW} \mathrm{h}$

$1 \%$ per year

$117 € / \mathrm{m}$

$1.5 \mathrm{~kW}$

$\eta_{\mathrm{E}}=50 \%$ and $\eta_{\mathrm{th}}=50 \%$

5 years (affects allowed cost of hydrogen)

Table 2

Main input data for calculation of hydrogen demand from FC-cars

Fuel cell system cost

Fuel cell power FC-car

Potential amount FC-cars

Efficiency of ICE-car

Efficiency of an FC-car

Annual mileage

Cost of gasoline (2004)

Cost increase gasoline

Tax on fuel

Tax $\%$ on hydrogen

Size of hydrogen refuelling stations ${ }^{\mathrm{a}}$

Role availability of $\mathrm{H}_{2}$ refuelling sta-

tions in FC-car purchase

Car lifetime

Cost for ICE
$2500 € / \mathrm{kW}$ in $2002,250 € / \mathrm{kW}$ in 2010 and $50 € / \mathrm{kW}$ in 2050 for mobile fuel cell cost

$40 \mathrm{~kW}$

$1.6 \% /$ year fleet growth, $6.7 \% /$ year fleet replacement

$0.62 \mathrm{kWh} / \mathrm{km}$ (equal to 11 gasoline for $14 \mathrm{~km}$ ) [3]

$0.26 \mathrm{~kW} \mathrm{~h} / \mathrm{km} \mathrm{[3]}$

$15,000 \mathrm{~km} /$ year

$0.355 € / 1$ : cost for production, distribution and marketing (equals the price of $1.29 € / 1$ at the forecourt)

$2 \%$ per year

$0.076 € / \mathrm{kWh}$ (both for hydrogen and gasoline)

In 2002 a tax exemption on hydrogen is assumed, starting from the year 2010 tax is $100 \%$.

In period 2002-2010, a linear relation is assumed

At one refuelling station, there are 500 FC-cars per refuelling station and at 20 refuelling stations there are $1500 \mathrm{FC}$-cars per refuelling station. A linear interpolation is made for an intermediate number of stations

$20 \%$ of potential if only local availability, another $30 \%$ at local and regional availability and last $50 \%$ if also national availability

15 years

$30 € / \mathrm{kW}$ (based on a $77 \mathrm{~kW}$ engine)

${ }^{\mathrm{a}}$ In 2005 an average Dutch refuelling station provided fuel for 1600 cars.

Table 3

Parameters for small-scale reforming

\begin{tabular}{ll}
\hline Reformer cost (2002) & $€ 2.3$ million \\
Hydrogen output & $631 \mathrm{~kg} / \mathrm{day}(\mathrm{LHV})$ \\
Efficiency & $70 \%(\mathrm{LHV})$ \\
Natural gas input & $3.4 \mathrm{~N} \mathrm{~m}^{3} /$ day $(\mathrm{LHV})$ \\
Increase natural gas price & $1.5 \%$ per year \\
Electricity input & $339 \mathrm{~kW} \mathrm{~h} /$ day \\
Increase electricity price & $1 \%$ per year \\
Learning curve parameter: $b$ & 0.1 \\
\hline
\end{tabular}

\section{Table 4}

Cost for hydrogen pipelines

\begin{tabular}{ll}
\hline National transportation pipelines & $600-2000 € / \mathrm{m}$ \\
Regional transportation pipelines & $500-1000 € / \mathrm{m}$ \\
Distribution pipelines refuelling stations & $180 € / \mathrm{m}$ \\
Distribution pipelines houses & $117 € / \mathrm{m}$ \\
\hline
\end{tabular}

\subsection{Development of hydrogen demand}

It is assumed that the choice for the hydrogen system or the reference system mainly depends on which of the systems can provide a required energy service at the lowest costs. These costs are made up of fixed costs, being the annual costs for the investment, and variable costs, including the costs for the energy carriers and the maintenance costs. In the model, for each year, the costs of the energy services supplied by the hydrogen systems are calculated excluding the cost of hydrogen. By subtracting these costs from the costs for the reference systems the allowed hydrogen costs are obtained. The main parameters used to calculate the allowed hydrogen cost are listed in Tables 1 and 2 for the stationary and transport application, respectively.

The allowed costs of hydrogen are compared with the production costs of hydrogen for a small-scale steam methane reformer (Halder Topsoe) with a hydrogen output of approximately $1 \mathrm{MW}$. For each year, the production costs of hydrogen 
are calculated based on the reformer's fixed and variable costs and on the number of reformers that are installed. The investment costs for the reformer are assumed to decrease according to a sort of learning curve, which is a function of the total number of reformers that are installed:

$I_{\text {reformer }}=I_{\text {reformer, } 2002} N_{\text {reformer }}^{-b}$,

where $I_{\text {reformer }}$ are the investment costs of a reformer, $I_{\text {reformer,2002 }}$ are the investment costs in the year 2002, $N_{\text {reformer }}$ is the number of reformers installed and $b$ is a dimensionless parameter that indicates the steepness of the learning curve. The main parameters used for calculation of the hydrogen costs are listed in Table 3. Projections on the increase in price of the energy carriers are included in the calculation [2]. As a result the hydrogen production cost for small-scale steam reforming were found to range from about $2.2 € / \mathrm{kg}$ today to about $2.6 \mathbf{\epsilon} / \mathrm{kg}$ in 2050. In the comparison of allowed hydrogen costs for the $\mu \mathrm{CHP}$ application with the production costs for hydrogen an amount in the range of $0.1-0.4 € / \mathrm{kg}$ is added to the latter to take into account the costs for the local hydrogen distribution infrastructure. ${ }^{3}$

In principle, if the cost for which hydrogen can be delivered is lower than the allowed costs for hydrogen, a demand for hydrogen will develop. However, in practice this will never be such a clear decision. Therefore, an adoption model is incorporated in an attempt to take into account the early adopters on the one hand, and the laggers on the other hand. In the case of adoption of FC-cars a further restriction is put in due to the initially limited availability of hydrogen refuelling stations. It is assumed that only $20 \%$ of the potential customers qualify for FC-car adoption if only a refuelling station is available on a local level. Another $30 \%$ qualifies if refuelling stations are also available on a regional level, and the remaining $50 \%$ only takes FC-cars into consideration if there is a network of refuelling station that covers the entire country.

\subsubsection{Stationary application of hydrogen}

It is assumed that the introduction of hydrogen is only an option for newly built houses or in case of renovation. There is no introduction of hydrogen in existing houses based on the assumption that adjustment of existing infrastructure will be disproportionally expensive. The total number of potential hydrogen houses is calculated for each year and for each of the 40 regions based on the current number of houses in a region, a general renovation rate of $1.5 \%$ per year and a building rate of $1.05 \%$ for new houses. The total number of houses in the starting year 2000 is 6.8 million.

A separate $\mu \mathrm{CHP}$ model is used to calculate the yearly hydrogen demand for an average Dutch household. For the calculations use is made of electricity and heat-demand profiles with a resolution of $15 \mathrm{~min}$, which cover a whole year. Year average heat and power demands for an average Dutch household are derived from current data and future projections [2] with linear interpolation and extrapolation for the other years.

\footnotetext{
${ }^{3}$ The length of a distribution pipeline per household varies as a function of the region considered. Cost of $117 € / \mathrm{m}$ are used for these types of pipelines.
}

The calculations are done for a heat-demand following system, meaning that if there is only a power demand, electricity from the public grid will be used. Also electricity is purchased from the grid, if there is both a heat and power demand, but the $\mu$ CHP system cannot produce the desired amount of electricity. Electricity produced in excess is supplied back to the grid. If the fuel cell cannot produce the desired amount of heat, a hydrogen peak burner is used. The results obtained from the $\mu \mathrm{CHP}$ model for an average Dutch household range from 550 to $450 \mathrm{~kg} / \mathrm{year}$ of hydrogen for a single-family house and from 430 to $350 \mathrm{~kg} /$ year for a multi-family house, for the years 2000 and 2050 , respectively.

\subsubsection{Transport application of hydrogen}

Potential FC-cars are newly sold cars. With a total number of cars of 6.7 million in 2000, the potential number of FC-cars is calculated for each year and for each region based on the current number of cars in a region, a general replacement rate of $6.7 \%$ per year and a growth rate of the fleet of cars of $1.6 \%$ per year. The relative distribution of cars over the 40 regions as well as the replacement and growth rates is assumed constant in the period between 2000 and 2050. Based on an annual mileage of $15,000 \mathrm{~km}$ and an efficiency $0.26 \mathrm{kWh} / \mathrm{km}$ for the FC-car [3] an annual hydrogen demand of $117 \mathrm{~kg}$ is taken into account per FC-car.

\subsection{Cost of hydrogen infrastructure}

Because of economy of scale benefits, the possibility of applying carbon capture and storage in case hydrogen is derived from fossil sources or biomass, and increased flexibility to incorporate hydrogen from renewable sources, the general idea is that in the end a more centralized hydrogen supply system will evolve with a large-scale hydrogen pipeline infrastructure. It is assumed that a hydrogen pipeline infrastructure will start to evolve if the large-scale centralized system can supply hydrogen at lower cost than the system with small-scale on-site production. To assess at what level of hydrogen demand this might happen the cost of hydrogen for the centralized system is calculated for the hypothetical case that hydrogen is supplied by a hydrogen pipeline infrastructure right from the start, instead of first being supplied by small-scale on-site facilities.

\subsubsection{Theoretical built-up of hydrogen infrastructure}

Important issues that need to be addressed for these calculations are the type and length of pipelines required for a fully developed hydrogen infrastructure, and the way the built-up of the infrastructure will take place as a function of hydrogen demand. With respect to type and length of pipelines data from the current Dutch natural gas infrastructure are used. The Dutch natural gas infrastructure consists of $4000 \mathrm{~km}$ high-pressure (43-63 bar) national transportation pipelines (NTPs), $6000 \mathrm{~km}$ medium-pressure (16-40 bar) regional transportation pipelines (RTPs) and finally $85,000 \mathrm{~km}$ low-pressure (1 bar) distribution pipelines. It is expected that the built-up of the infrastructure 
will take place gradually. The pipelines are therefore divided over the 40 regions, so that calculations can be made for each region separately:

- National transportation pipelines (NTPs): Lengths are calculated per region by multiplying the total length $(4000 \mathrm{~km})$ with the ratio of the surface area of the region and the total surface area of the regions.

- Regional transportation pipelines (RTPs): Lengths are calculated per region by multiplying the total length $(6000 \mathrm{~km})$ with the ratio of the surface area of the region and the total surface area of the regions.

- Distribution pipelines for houses (DH): Lengths are calculated per region by multiplying the number of households in a region with an overall average length per household and a region-specific factor, which takes into account variations in density of households between regions. ${ }^{4}$ Over the regions the length per household varies from 5 to $23 \mathrm{~m}$.

In addition to these types of pipelines distribution pipelines for refuelling stations (DRFS) are defined. This will probably be low- to medium-pressure pipelines. The length of these pipelines is estimated to be $3 \mathrm{~km}$ per refuelling station.

With respect to infrastructure built-up as a function of hydrogen demand, various correlations are developed. For the NTP it is assumed that the length of this type of pipeline does not depend on the hydrogen demand. From the moment that a hydrogen demand starts to develop this part of the infrastructure is required in case of a centralized system. Of course this pipeline will not be utilized efficiently when hydrogen demand is still low, but it would be much more expensive to adjust the pipeline over and over again when the demand for hydrogen increases.

In case of the DH and DRFS, linear correlations are assumed between the length of the pipelines and the number of houses and cars using hydrogen, viz.:

$L_{\mathrm{DH}}=L_{\mathrm{av}, \mathrm{H}} \cdot N_{\mathrm{H}}$,

where $N_{\mathrm{H}}$ is the number of houses in a region, and $L_{\mathrm{av}, \mathrm{H}}$ is the average pipeline length per house, which varies per region, and

$L_{\mathrm{DRFS}}=3 \cdot N_{\mathrm{RFS}}$,

where $N_{\text {RFS }}$ is the number of refuelling stations in a region, and an average of $3 \mathrm{~km}$ pipeline per refuelling station is assumed. The number of refuelling stations per region is a function of the number of FC-cars (see Table 2).

Finally, a non-linear correlation is used to describe the builtup of RTPs as a function of overall hydrogen demand, expressing an initially rapid growth of pipeline length at low hydrogen demands, which gradually slows down as the demand of

\footnotetext{
${ }^{4}$ With a low density of households in a region, the average length of the distribution pipeline from the household to the reformer is longer.
}

hydrogen increases:

$L_{\mathrm{RTP}}=L_{\mathrm{RTP}}$, fully developed $\left(\frac{Q}{Q_{\text {fully developed }}}\right)^{1 /(1+a)}$,

where $L_{\text {RTP }}$, fully developed is the length of the RTPs per region in a fully developed infrastructure $(6000 \mathrm{~km}), Q$ is the hydrogen demand in a particular year, $Q_{\text {fully developed }}$ is the hydrogen demand in a fully developed hydrogen infrastructure and $a$ is a non-dimensional variable. The value of 0.3 is chosen for the exponent. For the calculations it is assumed that a fully developed infrastructure corresponds to the case where $50 \%$ of the projected total amount of cars and houses in the year 2050, i.e. if 7.3 million cars and 5.6 million houses use hydrogen as energy carrier. This corresponds to a total hydrogen demand of about $3400 \mathrm{kton} / y e a r$, which is nearly 50 times the amount of commercially produced hydrogen in the Rotterdam area today.

\subsubsection{Cost of hydrogen infrastructure}

Cost ranges for the various types of hydrogen pipelines are obtained from literature on construction of natural gas pipelines [4-6]. Values at the higher end of the references were adopted for the cost calculations. In addition, it is assumed that the cost for NTPs and RTPs depends on the region in which they are constructed. Building density is seen as a measure of the amount of obstacles that one has to get around during construction and will affect the costs. Table 4 presents an overview of the cost data used. Where cost ranges are indicated the lower value is used for the region with the lowest building density, and the higher value is used for the region with the highest building density. A linear interpolation for the cost of these pipelines is made for regions with intermediate densities. Annual costs for the hydrogen pipeline infrastructure are calculated with a linear write-off over 40 years and an interest rate of $6 \%$.

\subsection{Hydrogen infrastructure development}

Results from model calculations indicate that the cost of hydrogen for small-scale on-site production are in the range of $2.2-2.6 € / \mathrm{kg}$. Typical large-scale hydrogen production costs are taken from literature and are reported to be about $1.1 € / \mathrm{kg}$ for natural gas reforming and about $1.2 € / \mathrm{kg}$ for production from coal gasification, both including carbon capture and storage [7]. The cost margin of $1.0-1.6 € / \mathrm{kg}$ between the two is a potential driver for development of a hydrogen pipeline infrastructure. As soon as the specific cost for a hydrogen infrastructure becomes smaller than the margin as indicated, construction of a hydrogen infrastructure becomes economically viable. In the model the specific costs of the hydrogen infrastructure are obtained by calculation of the ratio of the annual cost for the investment in the hydrogen pipeline infrastructure and the hydrogen demand in a particular year. As thus far a number of cost items are left out of the equation, like for instance O\&M costs for the hydrogen pipeline infrastructure, for the results in this paper it is assumed that the hydrogen infrastructure will only start to develop in a region if the specific costs for the hydrogen infrastructure become smaller than $0.5 € / \mathrm{kg}$. 
In addition to the economical boundary condition, two other conditions for the development of a hydrogen infrastructure with respect to geography are incorporated in the model:

- One of the regions must be indicated as a starting region from which an infrastructure can grow further to other regions. Obviously, the Rotterdam region is used as a default.

- Only the neighbouring regions of a region where an infrastructure is economically feasible can potentially develop a hydrogen infrastructure.

\section{Results}

Unless otherwise stated, the results presented in this section are obtained by using the input data as listed in Tables 1-4.

\subsection{Development of hydrogen demand}

Figs. 2 and 3 show the penetration of $\mu \mathrm{CHP}$ systems and FCcars, and the corresponding demand of hydrogen, respectively. According to the calculations a significant hydrogen demand may develop even when hydrogen is produced by small-scale on-site facilities. The application of hydrogen in $\mu \mathrm{CHP}$ systems in houses seems to offer a cost benefit over the reference system in a somewhat earlier stage than the application of hydrogen in an FC-car. Significant penetration of hydrogen fuelled $\mu \mathrm{CHP}$ systems starts about 10 years earlier than the penetration of hydrogen fuelled FC-cars. However, due to a higher replacement rate of cars compared to houses the penetration of FC-cars develops at a higher rate. The results show that under the conditions chosen, at 2050 the penetration rate for hydrogen in houses and hydrogen in cars is about $30 \%$ and $40 \%$, respectively. This corresponds to a hydrogen demand of about $1500 \mathrm{kton} / \mathrm{year}$ in houses and a demand of a little more than $700 \mathrm{kton} /$ year for cars. As a comparison, currently the commercial production of hydrogen in the Rotterdam area amounts to approximately $69 \mathrm{kton} / \mathrm{year}$.

\subsection{Cost of hydrogen infrastructure}

In Fig. 4 the development of various types of hydrogen pipelines is presented for the hypothetical case in which the demand of hydrogen as shown in Fig. 3 is supplied by a large-scale hydrogen pipeline infrastructure right from the start, instead of first being produced on-site. The figure clearly illustrates the assumption that in this supply scenario a full NTP structure is

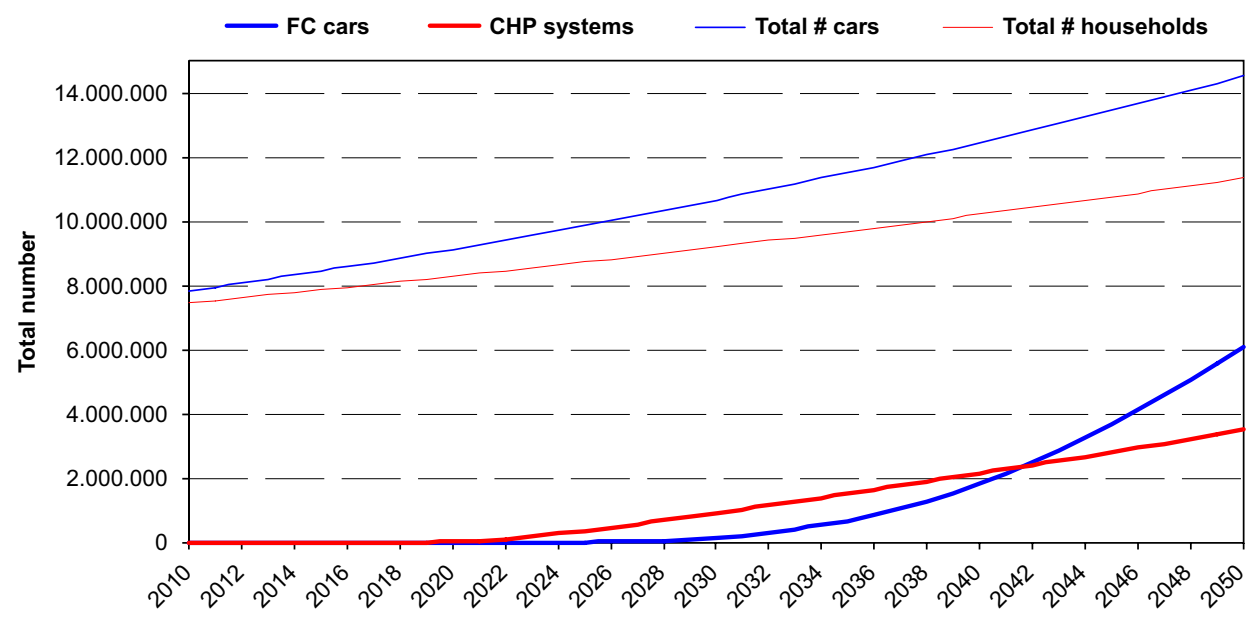

Fig. 2. Development of the numbers of CHP systems and FC-cars.

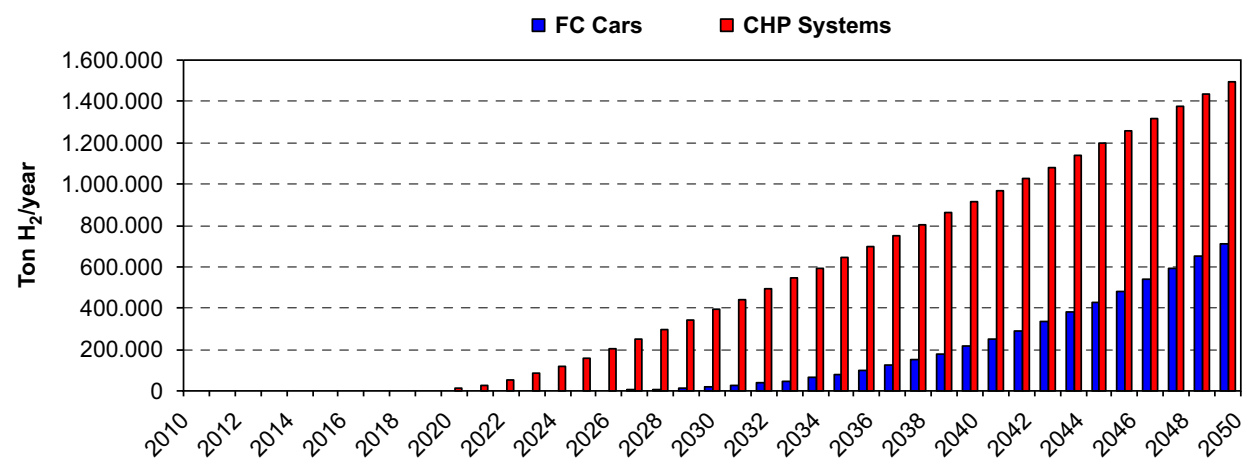

Fig. 3. Development of hydrogen demand for $\mu \mathrm{CHP}$ systems and FC-cars. 


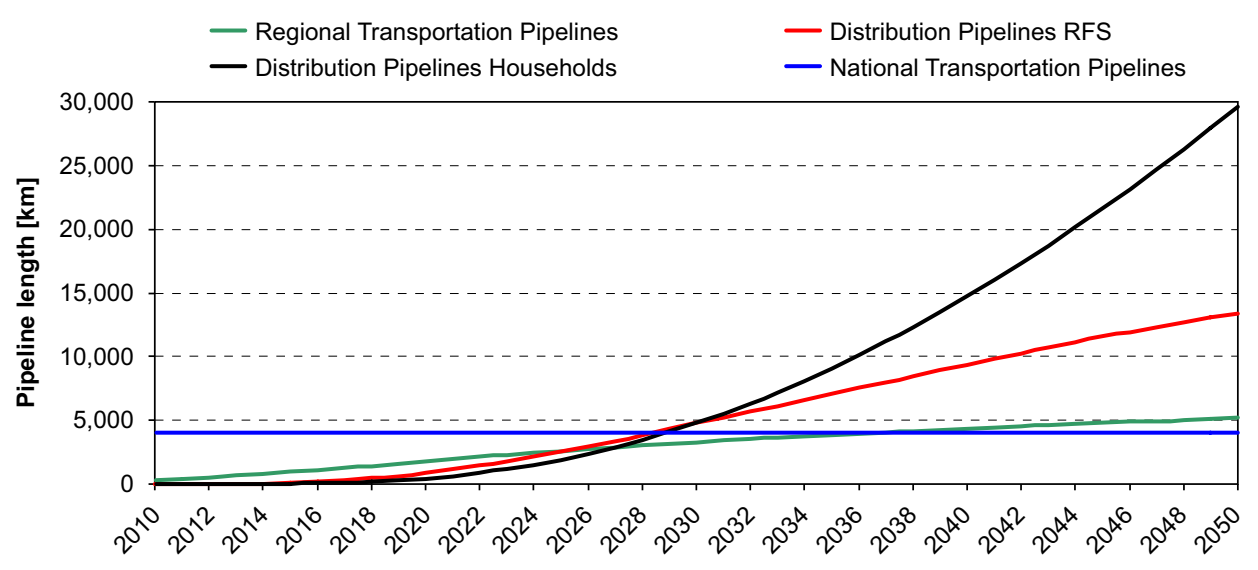

Fig. 4. Theoretical built-up of hydrogen pipelines.

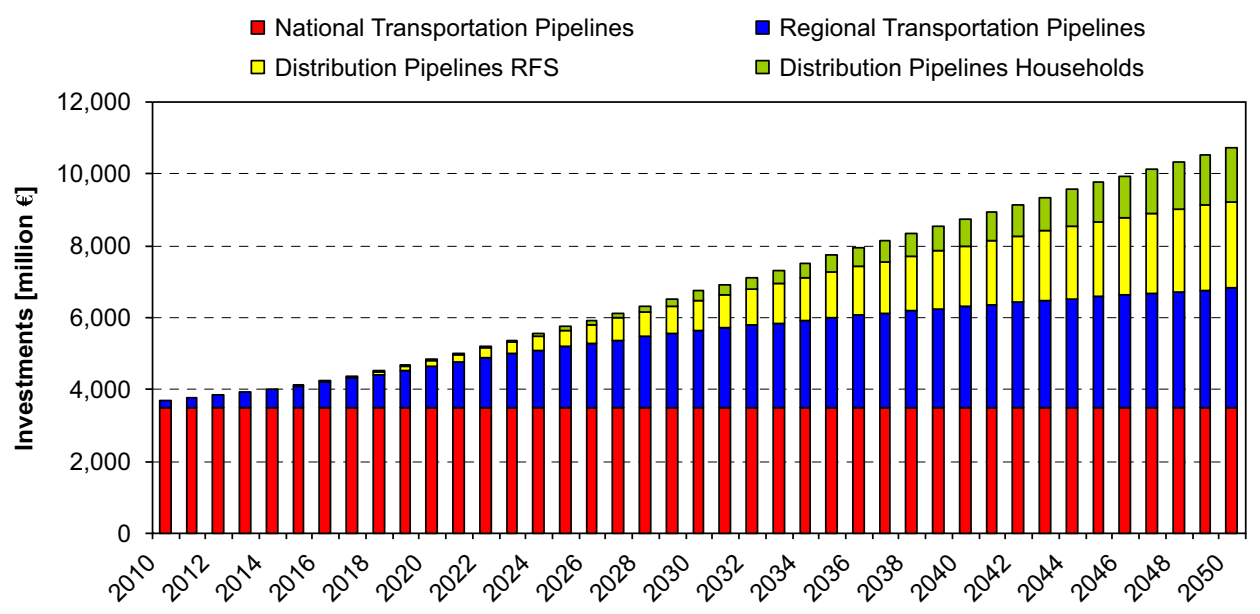

Fig. 5. Cumulative investments in hydrogen pipelines.

required, immediately after a hydrogen demand occurs somewhere. Also a significant amount of RTPs develops in an early stage. Even at a low hydrogen demand, the regional pipelines will need to have a large spatial coverage. Initially, the length of the DRFS is larger than for houses as the length for each refuelling station is set at $3 \mathrm{~km}$, while this number is in the range of 5-20 m for each house. However, in the end the length of the DH becomes the largest, as expected. Fig. 4 shows that under the conditions chosen the model does not yet result in a fully developed hydrogen infrastructure in 2050, as the length of the hydrogen DH $(30,000 \mathrm{~km})$ still is considerably smaller than the current number for natural gas distribution pipelines $(85,000 \mathrm{~km})$.

Fig. 5 shows the cumulative investment needed for the hydrogen pipelines. The calculations lead to cumulative investments of about 11,000 million euro in the year 2050. The investments for the low-pressure distribution grid (DH) are relatively small as only the investments for pipelines in the case of renovation are counted. In newly built situations a distribution grid, either for gas or heat, will have to be constructed anyway, and thus will not lead to additional investments. Based on the assumptions for a fully developed hydrogen infrastructure and the pipeline cost listed in Table 4, it is estimated that the total additional investments for hydrogen pipelines will be in the range of 12,000-20,000 million euros.

\subsection{Hydrogen infrastructure development}

It is assumed that if the hydrogen demand in a region has grown such that the cost contribution of a hydrogen infrastructure in the region becomes less than $0.5 € / \mathrm{kg}$ of hydrogen, the actual construction of such an infrastructure is economically viable. The results of these calculations are visualized in Fig. 6, with the colours indicating the year in which the criteria for implementation are met. The results show that implementation of the hydrogen infrastructure starts in 2027 in the Rotterdam area. After 5 years time, another five regions have met the criteria for implementation, and finally in 2050, more than 20 out of the 40 Dutch regions have a hydrogen infrastructure.

If the costs of hydrogen applications go down, the demand of hydrogen will increase. The cost of fuel cells is an important factor in the cost of hydrogen applications, and therefore an important parameter in the model. In Fig. 7, three different 
fuel cell cost curves for a $\mu \mathrm{CHP}$ fuel cell system are shown. The cost level for the year 2002 is kept constant at $5000 € / \mathrm{kW}$ and in 2050 all curves converge to $100 € / \mathrm{kW}(2500 € / \mathrm{kW}$ and $50 € / \mathrm{kW}$, respectively, for fuel cell systems for cars). The effect of the parameter variation on the development of the hydrogen infrastructure is visualized in Fig. 8. Clearly, as the fuel cell system costs decrease more rapidly, the model calculations

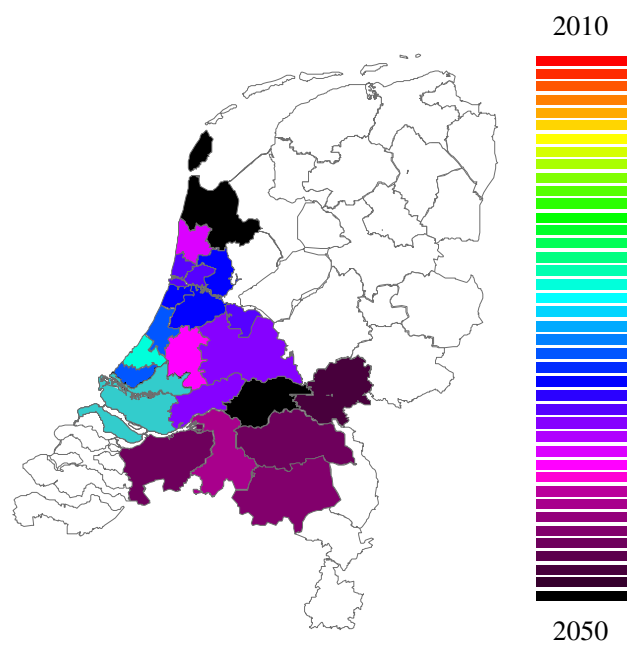

Fig. 6. Regions meeting the criteria for hydrogen infrastructure development. show that the development of a hydrogen infrastructure starts earlier and extends over an increasing number of regions. With actual fuel cell system cost at 2010 still being $2000 € / \mathrm{kW}$ the development only starts after 2030 and extends over 18 regions in 2050, while at cost of $250 € / \mathrm{kW}$ in 2010 the development starts about a decade earlier and extends over 25 regions in 2050 .

The current evaluation is limited to The Netherlands with a start in the Rotterdam area. A further development of the hydrogen infrastructure may take place if the development is allowed to start in other industrial regions besides the Rotterdam region, or regions that border on large industrial regions abroad, like the Antwerp region in Belgium or the Ruhr region in Germany. Another interesting idea for the transition towards the widespread use of hydrogen as an energy carrier is to start by using natural gas/hydrogen mixtures which can be applied safely in current natural gas end use applications and which can be distributed by the current natural gas distribution grid. This would concern a large number of customers, namely the current natural gas users, and would immediately generate a large demand for hydrogen. Preferably the mixture is prepared in regional or local grids with hydrogen produced in large-scale facilities. It might become economically viable to construct an NTP for pure hydrogen right from the start of the transition. Once this infrastructure is in place it could boost the demand and development of pure hydrogen applications. It could also

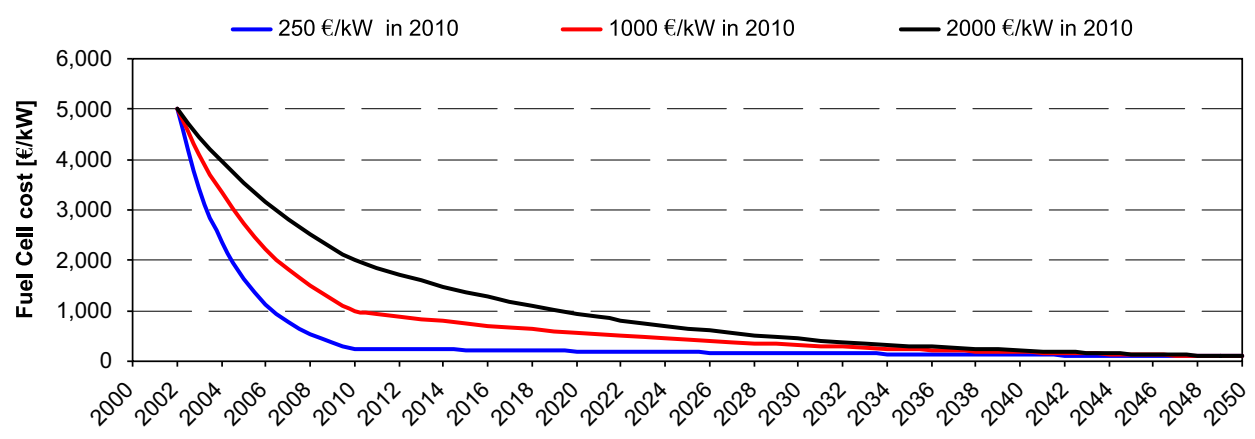

Fig. 7. Three cases for fuel cell cost decrease curves.
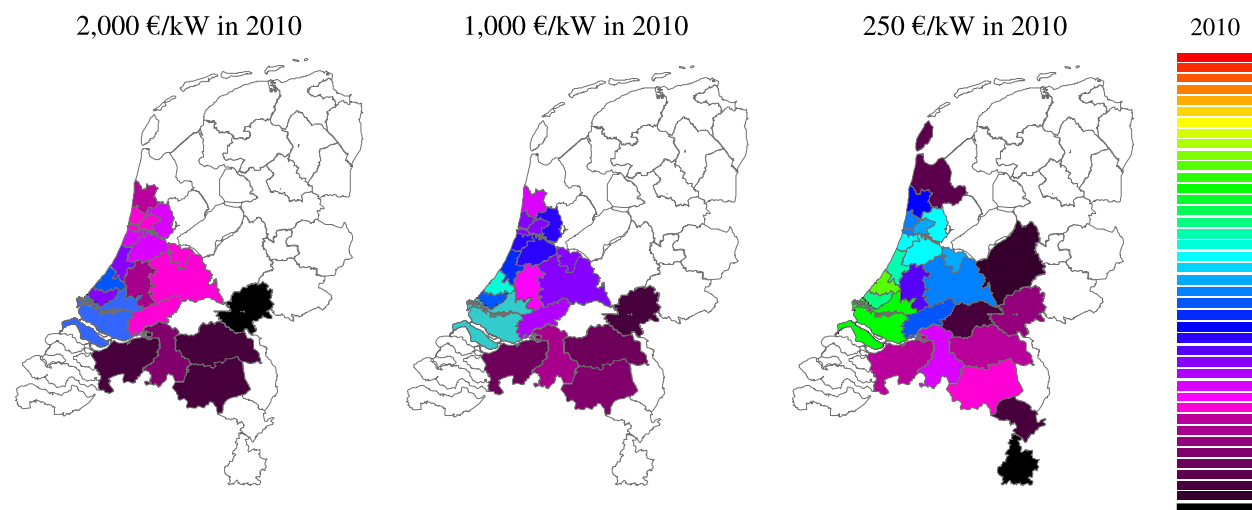

2050

Fig. 8. Effect of fuel cell system cost on the development of hydrogen infrastructure. 
boost the implementation of renewable sources into the energy system as it can serve as buffer or as outlet for excess energy from intermittent sources, like, for instance, electricity from offshore wind farms.

\section{Conclusions}

From the work on modelling current Dutch ideas for the transition towards the widespread use of hydrogen as an energy carrier, and simulation of the development of the hydrogen demand and the hydrogen infrastructure, the following is concluded:

- Based on a combination of current data and projections on small-scale hydrogen production through steam methane reforming, prices of energy carriers and fuel cell system cost, it appears that the use of hydrogen for the production of heat and power in houses through a $\mu \mathrm{CHP}$ system and for transportation by an FC-car can yield an economic advantage when compared to the conventional system. It thus seems possible that a hydrogen demand could develop using such a system, following the introduction of hydrogen in niche applications.

- According to results of the model developed, in 2050, the penetration of hydrogen in houses and hydrogen in cars is about $30 \%$ and $40 \%$, respectively. This corresponds to a hydrogen demand of about $1500 \mathrm{kton} / \mathrm{year}$ for houses and a demand of a little more than $700 \mathrm{kton} / \mathrm{year}$ for cars. This amount is a little more than 30 times the amount of commercially produced hydrogen today in the Rotterdam area (not counting hydrogen produced in refineries).

- The calculations indicate that with a system based on smallscale on-site production of hydrogen through steam methane reforming, the demand of hydrogen can develop to such an extent that the construction of a large-scale hydrogen pipeline infrastructure for the transport and distribution of hydrogen produced in large-scale production facilities becomes economically viable. The results indicate that in The Netherlands this situation may arise in 20-25 years from now.

- In 2050, the economic viability of a large-scale hydrogen pipeline infrastructure spreads over 20-25 of the 40 regions in which The Netherlands is divided for modelling purposes. The remaining regions typically are the ones that are the least densely populated. Up to 2050 the cumulative investments in hydrogen pipelines are calculated at about 11,000 million euro. Investments in hydrogen pipelines for a fully developed hydrogen infrastructure are estimated to be in the range of 12,000-20,000 million euros.

\section{References}

[1] L-B-Systemtechnik, coordinator HyWays. Assumptions, visions and robust conclusions from project phase 1, 2006. 〈http://www.hyways.de/docs/ Brochures_and_Flyers/HyWays_External_Document_02FEB2006.pdf

[2] European Commission. European energy and transport-trends to 2030. Luxembourg: Office for Official Publications of the European Communities; January 2003. 〈http://europa.eu.int/comm/dgs/energy_ transport/figures/trends_2030/index_en.htm $\rangle$

[3] CONCAWE, EUCAR. Well-to-wheels analysis of future automotive fuels and powertrains in the European context, Joint Research Centre of the European Commission (JRC, Ispra), January 2004.

[4] Mintz M, Molburg J, Folga S, Gillette J. Hydrogen distribution infrastructure. Article prepared for Argonne National Laboratory, Center for Transportation Research and Decision and Information Sciences Division, 2002.

[5] Parker N. Using natural gas transmission pipeline cost to estimate hydrogen pipeline cost. Masters thesis, Institute of Transportation studies, University of California, December 2004

[6] N.V. Nederlandse Gasunie. Annual Report, 2004.

[7] Foster-Wheeler. IEA greenhouse gas R\&D programme. Decarbonisation of fossil fuels. Report No. PH2/2, March 1996. 